did not follow-up the help-seeking individuals who underwent the clinical assessment at the prodromal services but were not considered at risk for psychosis (HR-). Consequently, it is completely obscure how the authors may have estimated the correct prevalence of false negatives (HR-, who developed psychosis over time) in their analysis. Given all the above concerns, I feel the results of this meta-analysis should be considered carefully as pilot data strongly undermined by significant methodological biases.

1 Chuma J, Mahadun P. Predicting the development of schizophrenia in high-risk populations: systematic review of the predictive validity of prodromal criteria. Br J Psychiatry 2011; 199: 361-6.

2 Yung AR, Phillips L, Yuen HP, Francey SM, McFarlane CA, Hallgren M, et al. Psychosis prediction: 12 months follow up of at risk (prodromal) group. Schizophr Res 2003; 60: 21-32.

3 Yung AR, Phillips L, Yuen HP, McGorry PD. Risk factors for psychosis in an ultra high-risk group: psychological and clinical features. Schizophr Res 2004; 67: 131-42.

4 Yung AR, Phillips L, Yuen HP, McGorry PD, Kelly D, Dell'olio M, et al. Mapping the onset of psychosis: the comprehensive assessment of at risk mental states. Aust NZ J Psychiatry 2005; 39: 964-71.

5 Yung AR, Nelson B, Stanford C, Simmons MB, Cosgrave EM, Killackey E, et al. Validation of 'prodromal' criteria to detect individuals at ultra high risk of psychosis: 2 year follow up. Schizophr Res 2008; 105: 10-7.

6 Woods SW, Addington J, Cadenhead KS, Cannon TD, Cornblatt BA, Heinssen $\mathrm{R}$, et al. Validity of the prodromal risk syndrome for first psychosis: findings from the North American Prodrome Longitudinal Study. Schizophr Bull 2009; 35: 894-908.

7 Cannon TD, Cadenhead K, Cornblatt B, Woods SW, Addington J, Walker E, et al. Prediction of psychosis in youth at high clinical risk: a multisite longitudinal study in North America. Arch Gen Psychiatry 2008; 65: 28-37.

Paolo Fusar-Poli, Department of Psychosis Studies, Institute of Psychiatry, London, UK. Email: paolo.fusar-poli@kcl.ac.uk

doi: 10.1192/bjp.200.3.254a

Authors' reply: Dr Fusar-Poli identified a number of studies reporting follow-up transition rates, which is not the same as predictive the validity of the tests or criteria. Most, if not all, of the studies he identified did not have information on predictive attributes of the tests or criteria, such as sensitivity and specificity. However, they had useful information on transition rates. From these it is impossible to know how good the tests/criteria were in ruling in or out the risk of developing schizophrenia from prodromal symptoms, since these studies were not systematically following up those who tested negative to the test.

Dr Fusar-Poli raised another important issue regarding overlapping of samples. We checked for double publication, but not necessarily overlapping of samples. We were interested in knowing how good the test is in predicting schizophrenia in high-risk populations. We therefore were interested in diagnostic attributes of a test in each study/subsample. The values for sensitivity and specificity for Yung et al (2003) ${ }^{1}$ and Yung et al (2004) $)^{2}$ were not identical. For the purposes of predictive validity of a test, these are two different studies. Yung et al $(2005)^{3}$ had a follow-up of 6 months $(n=105)$ and Yung et al $(2008)^{4}$ had a follow-up of 24 months $(n=292)$. Again, these are different studies, we are not sure whether there was overlapping of samples in these two but we don't see how this would affect how good the test is at ruling in or out the risk of developing schizophrenia. The same can be said with studies by Cannon et $a l^{5}$ and Woods et al, ${ }^{6}$ the diagnostic attributes of the Cannon study were not identical to Woods' study.

Dr Mitchell raises important points regarding the predictive validity of prodromal criteria. In particular, Dr Mitchell is right to suggest that the positive predictive value and negative predictive value statistics are more intuitively informative than sensitivity and specificity, and so their reporting would have been beneficial.
We also agree that assessing the clinical usefulness of prodromal criteria requires further consideration. We plan to further examine this important question in a subsequent paper. We welcome Dr Mitchell's proposal for a randomised study where high-risk patients are randomised to predicting psychosis with or without formal tests for prodromal criteria.

1 Yung AR, Phillips $L$, Yuen HP, Francey SM, McFarlane CA, Hallgren M, et al. Psychosis prediction: 12 months follow up of at risk (prodromal) group. Schizophr Res 2003; 60: 21-32.

2 Yung AR, Phillips L, Yuen HP, McGorry PD. Risk factors for psychosis in an ultra high-risk group: psychological and clinical features. Schizophr Res 2004; 67: 131-42.

3 Yung AR, Phillips L, Yuen HP, McGorry PD, Kelly D, Dell'olio M, et al. Mapping the onset of psychosis: the comprehensive assessment of at risk mental states. Aust NZ J Psychiatry 2005; 39: 964-71.

4 Yung AR, Nelson B, Stanford C, Simmons MB, Cosgrave EM, Killackey E, et al. Validation of 'prodromal' criteria to detect individuals at ultra high risk of psychosis: 2 year follow up. Schizophr Res 2008; 105: 10-7.

5 Cannon TD, Cadenhead K, Cornblatt B, Woods SW, Addington J, Walker E, et al. Prediction of psychosis in youth at high clinical risk: a multisite longitudinal study in North America. Arch Gen Psychiatry 2008; 65: 28-37.

6 Woods SW, Addington J, Cadenhead KS, Cannon TD, Cornblatt BA, Heinssen $\mathrm{R}$, et al. Validity of the prodromal risk syndrome for first psychosis: findings from the North American Prodrome Longitudinal Study. Schizophr Bull 2009; 35: $894-908$.

Jefter Chuma, community psychiatric nurse, Prem Mahadun, clinical studies Jefter Chuma, community psychiatric nurse, Prem Mahadun, Clinical stud
officer, Trafford Crisis Resolution and Home Treatment Team, NIHR Mental Health Research Network (North West Hub), Manchester, UK. Email: Jefta.Chuma@trafford.nhs.uk

doi: 10.1192/bjp.200.3.255

\section{Abortion, mental health and charges of guilt by association}

Coleman's meta-analysis of abortion and mental health studies ${ }^{1}$ was harshly criticised in three letters by five authors (Robinson, Stotland, Nadelson, Coyne, and Littell) who all cited an Ethics \& Medicine article $^{2}$ I wrote (not Coleman) as evidence that Coleman's study cannot be trusted. My full response ${ }^{3}$ is summarised as follows.

First, Robinson's ${ }^{4}$ assertion that I am Coleman's 'leader' is nonsense. We have no institutional, financial or personal entanglements. Second, I gathered data that required the analysis of research psychologists. I am thankful that Coleman agreed to analyse it and help present it in a scientifically accurate and impartial manner. As a biomedical ethicist, I explore the intersections of medicine, science, philosophy, theology, ethics and the law. When writing papers intended for each of these fields, I seek to use the language and tools appropriate to each field.

Third, the cited article was a response to a pro-life philosopher who argued that any evidence of emotional suffering of women following abortion is essentially irrelevant to the moral argument against abortion and counterproductive to pro-life efforts. ${ }^{5}$ The core of my response was that Christians have an obligation to 'consistently demonstrate as much concern for women as for their unborn children', and that 'our advocacy for women must be consistent and unconditional both for those who are facing crisis pregnancies and for those who have had abortions'. I further argued that 'the harm abortion does to women is just as real as that done to the human fetus.'

Fourth, it also reflected my sincere belief that abortion involves substantial dangers to specific subgroups of women. Unfortunately, critics have distorted this into the charge that I seek to scare women with exaggerated risks. ${ }^{6}$ That is untrue. There are real risks, especially for certain higher-risk groups. ${ }^{7}$ Women 
should be told of the truth regarding statistically significant findings. These should be neither exaggerated nor minimised.

Finally, women who dare to express emotional trials following an abortion face rejection from people on both sides. A few pro-lifers harshly dismiss these women as 'sinners' who deserve a lifetime of grief. Conversely, at least a few pro-choicers dismiss their grief as 'whining' or 'rare', or suggest that only women mentally unstable prior to their abortions would complain so much. By contrast, the post-abortion healing movement simply asks those on both sides to respect the experiences of women grieving a past abortion. But even this pro-healing position is attacked. Pro-choicers accuse us of manipulating gullible women into falsely blaming unrelated life problems on their abortions. ${ }^{6}$ Some pro-life advocates, meanwhile, accuse us of encouraging an unprincipled, narcissistic worldview that diminishes the moral absolutes regarding the sanctity of life. ${ }^{5}$

To my mind, the question of whether abortion is the sole, direct cause of certain mental illnesses is far less important than the fact that many self-aware women want help coping with a past abortion experience. ${ }^{7}$ Why is it so hard to simply accept their self-assessments and stated needs? Women deserve better.

\section{Declaration of interest}

\section{R. is Director of the Elliot Institute, USA.}

1 Coleman PK. Abortion and mental health: quantitative synthesis and analysis of research published 1995-2009. Br J Psychiatry 2011; 199: 180-6.

2 Reardon DC. A defense of the neglected rhetorical strategy (NRS). Ethics Med 2002; 18: 23-32.

3 Reardon DC. Abortion and mental health deniers' attack and distract strategy - after abortion. After Abortion, 2011; October 22 (http://afterabortion.org/ 2011/do-not-publish/).

4 Robinson GE, Stotland NL, Nadelson CC. Re: Abortion and mental health: quantitative synthesis and analysis of research published 1995-2009. (E-letter). Br J Psychiatry 2011; September 22.

5 Beckwith FJ. Taking abortion seriously: a philosophical critique of the new anti-abortion rhetorical shift. Ethics Med 2001; 17: 155-66.

6 Baezlon E. Is there a post-abortion syndrome? New York Times Magazine 2007; January 21.

7 Burke T, Reardon DC. Forbidden Grief: The Unspoken Pain of Abortion. Acorn Books, 2002.

David Reardon, Director, Elliot Institute, Springfield, Illinois, USA. Email: bmj@mine4ever.net

doi: $10.1192 /$ bjp.200.3.255a

\section{The fall of the aypticals?}

In his editorial arguing that atypical antipsychotics can no longer be regarded as having advantages over conventional drugs, Kendall $^{1}$ makes two statements which do not do justice to the available evidence.

First, he states: 'With the exception of clozapine for treatmentresistant schizophrenia, the atypicals, as a group of antipsychotics, are no more efficacious for schizophrenia than the typicals, whether it is chronic or acute, for first or subsequent episodes, for the acute episode or for promoting recovery'. This is supported by a reference to the updated National Institute for health and Clinical Excellence (NICE) guideline for schizophrenia, ${ }^{2}$ which in turn based its conclusions on a series of meta-analyses carried out by the National Collaborating Centre for Mental Health (NCCMH; www.nccmh.org.uk). The problem here is that two other meta-analyses have reached different conclusions. In 2003, Davis et $a l^{3}$ found that, apart from clozapine, three atypicals showed significant superiority over conventional antipsychotics: risperidone (22 studies, effect size (ES) 0.25), olanzapine (14 studies, ES $=0.21)$ and amisulpride (12 studies, $E S=0.29$ ). Six years later, Leucht et $\mathrm{al}^{4}$ had closely similar findings for olanzapine (28 studies, ES $=0.28$ ) and amisulpride ( 13 studies, $E S=0.31$ ); the effect size had become smaller for risperidone, but it was still significant (34 studies, ES $=0.13$ ).

One reason why the NICE/NCCMH meta-analysis may have reached negative conclusions concerning these three drugs is that it included fewer studies. The outcome measure used by Davis et $a l^{3}$ and Leucht et $a l^{4}$ was reduction in total symptom scores, based on pooled data from the Positive and Negative Syndrome Scale (PANSS), Brief Psychiatric Rating Scale (BPRS) and CGI (Clinical Global Impression) scale, and from the PANSS and BPRS respectively. In the NICE/NCCMH meta-analyses there were only 17 studies of risperidone, 10 of olanzapine and 4 of amisulpride in which the drug was compared with a conventional antipsychotic on any of these outcome measures. Data were also pooled separately for studies carried out on patients with first-episode schizophrenia, on those with acute exacerbations or recurrences, and on those with treatment-resistant illness. As a result, the maximum number of studies included in any of the NICE/ NCCMH meta-analyses of overall symptoms for these three atypicals was six, and several contained only one or two studies.

Later in the article, Kendall cites approvingly a meta-analysis by Geddes et $a l^{5}$ in 2000, which found evidence that the superiority of atypicals (including clozapine) was an artefact of the high dose of the typical antipsychotic used as a comparator in some of the trials. These authors used meta- regression to examine the predictive value of haloperidol dose (23 studies) or chlorpromazine dose ( 7 studies) on the outcome of total symptom scores. In both cases, the findings were significant: an observed advantage in favour of atypicals disappeared as the dose of the comparator drug decreased. Davis et $a^{3}$ subsequently explored the effect of comparator dose in their meta-analysis. The results of several different analyses led them to conclude that there was no significant effect of haloperidol in a larger data-set of studies. Leucht $e t a l^{6}$ also failed to find a significant effect of chlorpromazine comparator dose in another meta-analysis carried out at around the same time. Geddes et $\mathrm{al}^{7}$ argued that a significant effect of comparator dose could be re-instated in this latter meta-analysis by using their own meta- regression technique; in their author reply, Leucht $\mathrm{et}^{\mathrm{P}} \mathrm{l}^{7}$ countered that the effect was not significant when a variety of other statistical techniques were used, indicating that the finding was not robust.

Kendall states that the comparator drug effect has been 'neither confirmed nor disproved by later meta-analyses'. An arguably more accurate conclusion is that it was an early finding which has not stood the test of time.

1 Kendall T. The rise and fall of the atypical antipsychotics. Br J Psychiatry 2011; 199: 266-8.

2 National Institute for Health and Clinical Excellence. Schizophrenia: Core Interventions in the Treatment and Management of Schizophrenia in Adults in Primary and Secondary Care (Update). NICE, 2009.

3 Davis JM, Chen N, Glick ID. A meta-analysis of the efficacy of secondgeneration antipsychotics. Arch Gen Psychiatry 2003; 60: 553-64.

4 Leucht S, Corves C, Arbter D, Engel RR, Li C, Davis JM. Second-generation versus first-generation antipsychotic drugs for schizophrenia: a metaanalysis. Lancet 2009; 373: 31-41.

5 Geddes J, Freemantle N, Harrison P, Bebbington P. Atypical antipsychotics in the treatment of schizophrenia: systematic overview and meta-regression analysis. BMJ 2000; 321: 1371-6.

6 Leucht S, Wahlbeck K, Hamann J, Kissling W. New generation antipsychotics versus low-potency conventional antipsychotics: a systematic review and meta-analysis. Lancet 2003; 361: 1581-9. 